\title{
Activity of Kalanchoe integra against Selected Pathogenic Bacteria
}

\section{Umuhoza MR, Habyarimana T and Niyonzima FN*}

Department of Biomedical Laboratory Sciences, INES Ruhengeri, Rwanda

*Corresponding author: Francois N Niyonzima, INES Ruhengeri, PO Box 155 Musanze, Rwanda, Tel: +250788536610; Email: niyofra@yahoo.com

\section{Research Article \\ Volume 6 Issue 2}

Received Date: June 08, 2021

Published Date: June 28, 2021

DOI: $10.23880 /$ oajmb-16000197

\section{Abstract}

Kalanchoe integra is a plant that belongs to the Crassulaceae family. In English, the international common name is never die. There are 1500 species of perennial herbs or low shrubs in the genus. Antibiotic resistance is currently at an alarmingly high level. Phytocompounds of Kalanchoe sp. were reported as antimicrobial agents. In Rwanda, no study about antimicrobial activity of $K$. integra extracts against bacteria-causing diseases was conducted. Therefore, the aim of the present study was to investigate the antimicrobial effectiveness of $K$. integra phytochemicals against clinically selected pathogenic bacteria (Shigella sonnei, Haemophilus influenza, Salmonella typhi, Escherichia coli, Staphylococcus aureus and Streptococcus pneumoniae). Maceration technique was used to prepare the leaf and stem extracts using methanol, water and petroleum ether. Phytochemical screening tests revealed that flavonoids, phenolics, and saponins were present in the leaves and stem extracts by using methanol and water. However, tannins were only present in the leaves. No phytochemicals observed by the using petroleum ether. The antimicrobial activity of clinically selected pathogenic bacteria (S. aureus, Haemophilus influenza, Streptococcus pneumoniae, Shigella sonnei, S. typhi, and E. coli) was tested using the agar well diffusion procedure. In order to analyse the data, SPSS was used. The means of inhibition zones of leaf and stem extracts were studied using a two-way ANOVA and both of them showed statistical significant with p-values of 0.03 and 0.04 , respectively. Antibacteria activity results showed that $S$. typhi was more sensitive than other tested bacteria. The largest zone of inhibition $(20.5 \mathrm{~mm})$ was observed with methanol leaf extract against $S$. typhi, and the smallest inhibition was observed with $H$. influenza (12.5 mm). Leaf and stem extracts using methanol solvent showed activity on all bacteria used in the study except on $S$. sonnei. Leaf and stem water extracts significantly inhibit the growth of $E$. coli with inhibition zone of $14.5 \mathrm{~mm}$ and $11.5 \mathrm{~mm}$, respectively, while petroleum ether had no effect on any bacterium. Thus, the present medicinal plant could serve as antibiotics as it showed an important activity against studied bacteria. The study has to continue with other plant parts and other bacteria-causing diseases to make the process cost-effective.

Keywords: K. Integra; Solvent; Phytochemicals; Clinical Bacteria

\section{Introduction}

Plants absorb water and inorganic compounds with the help of the roots. The leaves then produce nutrients by photosynthesis. Many plants and phytosubstances from them are used to cure diseases caused by microorganisms. It has been found that medicinal plant has played a vital role in disease management since prehistoric. Most of the population in under development countries utilizes medicinal plants as drug agents. In these countries', conditions like epilepsy, psychosis, pain, etc. are usually treated using herbs. Cholera, gonorrhoea, and typhoid are some of the diseases cured by 


\section{Open Access Journal of Microbiology \& Biotechnology}

phytocompounds of medicinal plants [1]. In these medicinal plants, there is plant called Kalanchoe integra. It is a fleshy perennial plant and lives more than two years. It is classified in crassulaceae family. It sometimes includes Kalanchoe lacinata. Their common name is Never Die found in tropical to temperature areas. The tannins and flavonoids of $K$. integra were reported to cure the bronchial asthma [2].

The worldwide increase in antibiotic resistance to many Gram negative and positive bacteria is a big problem [3]. The emerging or spreading of new resistance mechanisms of bacteria caused by the less effective of antibiotics are increasing worldwide. This is serious problem since most of the killer diseases such as tuberculosis, pneumonia, septicemia, gonorrhea, foodborne diseases and diarrhea are caused by those resisting bacteria [4]. S. aureus and $S$. pneumoniae are Gram positive bacteria that may cause skin infection, endocarditis and osteomyelitis. These bacteria are resistant to penicillin and other antibiotics related to this. S. pneumoniae mainly found in children when colonize nasopharynx can lead to infection by spreading the tissue to cause acute otitis media [5]. Worldwide rate of multidrug resistance of $S$. typhi has increased from 34.2 to $48.5 \%$ [6]. This leads to serious diseases in humans especially immunecompromised individuals. It has reported that 30 to $60 \%$ of hospitalized patients are because of antibiotic resistance [7].

People in several parts of the world, especially Africa, are utilizing plant extracts to treat themselves from different microbial infections caused by microorganisms like bacteria whenever they became sick or injured in their environment. Although, many studies have been carried out to determine antibiotic susceptibility pattern on different bacteria [8-13], the determination of effectiveness of medicinal plants against different bacteria species is a continuous exercise. Antimicrobial activity of $K$. integra extracts against bacteria that cause diseases was not studied in Rwanda. That why the study of $K$. integra against clinical bacteria is needed. The objective of the present study was thus to assess the antimicrobial effectiveness of Kalanchoe integra phytosubstances against S. sonnei, H. influenza, S. typhi, E. coli, S. aureus and S. pneumoniae.

\section{Materials and Methods}

\section{Chemicals, Plant and Microorganisms}

All chemicals and reagents utilized were analytical grade. They were purchased from Sigma-Aldrich (USA) and Hi Media Laboratories (Mumbai, India). K. integra leaves and stem were collected from the INES- Ruhengeri botanical garden. The microbes used were $S$. typhi, S. sonnei, $H$. influenza, E. coli, S. pneumonia and S. aureus. They were from Rwanda biomedical center.

\section{Preparation of Kalanchoe Integra Extract}

Leaves and stem were washed and dried at room temperature $\left(24^{\circ} \mathrm{C}\right)$ for one week. They were then put in hot air oven for $30 \mathrm{~min}$ at $100^{\circ} \mathrm{C}$ for full dryness. $4 \mathrm{~kg}$ of $\mathrm{K}$. integra leaves and $2 \mathrm{~kg}$ of stem were blended differently to form powder using sample mill machine. The three solvent used were 95\% methanol, 96\% petroleum ether, and distilled water. $20 \mathrm{~g}$ of leaves powder was dissolved in $200 \mathrm{ml}$ of each solvent. The same procedure was repeated with stem powder. They were allowed to stand on macerated machine for 5 days until soluble matter was dissolved. Each mixture was sieved by using triple layer of gauze to remove pigments. Haploid machine was used to evaporate solvent [14].

\section{Screening of Phytochemicals}

The qualitative phytochemical analysis of $K$. integra crude extracts was performed to check the presence of alkaloids, saponins, glycosides, resins, phenols, tannins and flavonoids. Phenols were detected by adding $0.5 \mathrm{ml}$ of ferric chloride into stem crude extract and another $0.5 \mathrm{ml}$ of ferric chloride into $1 \mathrm{ml}$ of leaves extract. The presence of phenolic compounds was indicated by the occurrence of a bluish green color. Tannins were detected by pouring $2.5 \mathrm{ml}$ of distilled water into $0.5 \mathrm{~g}$ of leaves extract and another into $0.5 \mathrm{ml}$ of the stem extract. After that, the solution was filtered and divided into two parts. $1 \%$ lead acetate was added to the first part and the presence of white sediment was a positive test. $1 \%$ of ferric chloride solution was added to the second part and the appearance of bluish green color was positive test [15].

Saponins were detected by adding 5 drops of extract into water. After shaking, the mixture was left to stand for $15 \mathrm{~min}$. The presence of saponins was indicated by the foam formation. Flavonoid concentrations were determined by combining $50 \mathrm{mg}$ of powder, $5 \mathrm{~mL}$ of distilled water, and $2 \mathrm{~mL}$ of $\mathrm{NaOH}$. The presence of flavonoid was indicated by a color change, from yellow to colorless, after adding few drops of $\mathrm{HCl}$. For glycosides, $10 \mathrm{ml} \mathrm{of} \mathrm{H}_{2} \mathrm{SO}_{4}$ was mixed into $1 \mathrm{ml}$ of extract. Fehling's solution (10 mL) was added. The absence of brick red precipitate indicated a positive test. Alkaloids were detected by mixing $50 \mathrm{mg}$ of powder with $10 \mathrm{ml} \mathrm{HCl}$. The negative test was shown by the absence of turbidity after adding 2 drops of Mayer's reagent [15].

\section{Sub-culturing of Microorganisms}

$H$. influenza, S. aureus and S. sonnei, E. coli were subcultured on nutrient agar (NA). S. pneumoniae was subcultured on blood agar and $S$. typhi was sub-cultured on agar containing xylose, lysine, and deoxycholate. Incubation was performed on the inoculated Petri dishes at $37^{\circ} \mathrm{C}$ for $24 \mathrm{~h}$. 


\section{Open Access Journal of Microbiology \& Biotechnology}

They were stored at $4^{\circ} \mathrm{C}$.

\section{Antimicrobial Activity of Kalanchoe integra Leaves and Stem Extract Against Pathogenic Bacteria}

Microbial suspension was prepared by mixing 2 loops full of colony with $4 \mathrm{ml}$ of normal saline in sterile tube. It was then compared with $0.5 \mathrm{McF}$ arland standards for checking the turbidity. Mueller hinton agar (MHA) media were prepared and sterilized. Agar well diffusion method was performed by puncturing the holes of $6 \mathrm{~mm}$ in the MHA plates. After that, microbial suspension was inoculated in to punctured media. Prepared extracts were put in all holes according to their concentrations. The positive control used was levoflaxin $(5 \mu \mathrm{g} / \mathrm{ml})$ for all the pathogenic bacteria, while solvent without extract was used as negative control. The Petri dishes were incubated for $24 \mathrm{~h}$ at $37^{\circ} \mathrm{C}$. Inhibition zones were measured in $\mathrm{mm}$.

\section{Statistical Analysis}

All measurements were done in duplicate. For data analysis, SPSS version 22 was utilized. Two-way analysis (ANOVA) and t-test were applied to compare the means of various extract parameters. The statistical analysis was performed at the $95 \%$ confidence level and p-values less than 0.05 were considered statistically significant.

\section{Results and Discussion}

\section{Screening of Phytochemicals from Kalanchoe integra.}

In the present study, the activity of $K$. integra against selected pathogenic bacteria was assessed. The plant parts selected were leaves and stem (Table 1). Similarly, stem $[12,13]$ and leaves $[9,10,14,16-19]$ were also used. However, roots were also utilized by some authors $[9,16,17]$. Therefore, to extract phytocompounds of $K$. integra that may have antimicrobial activities, any plant part can be utilized. Methanol, petroleum ether, and water were used as extraction solvents (Table 1). Methanol as polar solvent was the solvent of choice in most cases [8-11] followed by non-polar solvent like petroleum ether $[9,16,17]$. Abdellaoui, et al. [8] and Kolodziejczyk-Czepas, et al. [20] and Stochmal preferred to use ethanol, whereas water was used by Biswas, et al. [9] and Richwagen, et al. [13] Thus, various solvents are tried during screening, and the ones with high yield of phytocompounds are chosen. Many researchers prefer to use polar and non-polar or a mixture of them.

Medicinal plants are the most useful for curing human disease because of phytochemical constituents' presence [21]. After screening, using methanol and water as solvents, the leaves of $K$. integra revealed the presence of flavonoids, tannins, phenols, and saponins. Flavonoids, tannins, and phenols were found in the stem with water and methanol solvents. However, by using petroleum ether, there was no presence of any phytochemical (Table 1). Similarly, flavonoids were reported as chief phytosubstance extracted in Kalanchoe sp. $[8,9,10,16,17,19]$. In leaves and stem, saponins [17] and phenols were also seen [8,12,22]. Only Quazi, et al. and Rashmi, et al. $[16,17]$, reported the presence of tannins. Although $K$. integra lacked alkaloids and glycosides (Table $1)$, alkaloids and glycosides $[8,16,17]$ were present in other Kalanchoe $s p$. Like in the present study, the presence of resins was not reported by any researcher. Thus, $K$. integra can be screened with polar solvents like water and methanol in order to get phytochemicals that may have antimicrobial activities.

\begin{tabular}{|c|c|c|c|c|c|c|c|}
\hline & & \multicolumn{3}{|c|}{ Leaves } & \multicolumn{3}{c|}{ Stem } \\
\hline Substances & Reagents & Methanol & Petroleum ether & Water & Methanol & Petroleum ether & Water \\
\hline Phenols & Ferric oxide & + & - & + & + & & - \\
\hline Tannins & $\begin{array}{c}\text { Lead acetate, ferric } \\
\text { chloride, distilled water }\end{array}$ & & & & & & \\
\hline Glycosides & $\begin{array}{c}\text { Fehling's solution, 50\% } \\
\mathrm{H}_{2} \mathrm{SO}_{4}\end{array}$ & - & - & - & - & & \\
\hline Saponins & Distilled water & + & - & + & + & & - \\
\hline Alkaloids & Wagner reagent & - & - & - & - & & - \\
\hline Flavonoids & Alkaline & + & - & + & + & & - \\
\hline Resins & Ethyl alcohol & - & - & - & - & & - \\
\hline
\end{tabular}

Table 1: Phytochemicals screened from extracts of Kalanchoe integra leaves and stem.

+: present, -: absent 


\section{Open Access Journal of Microbiology \& Biotechnology}

\section{Antibacterial Activity of Kalanchoe Integra against Selected Pathogenic Bacteria}

Phytochemicals of Kalanchoe sp. were reported as antimicrobial, anti-asmathic, anti-inflammatory, antihelmenthic, antioxidant, and anti-tumor agents $[9,10,12$ $14,16,18,19]$. The purpose of this study was to show that $K$. integra is effective as an antibacterial agent against $S$. aureus, $E$. coli, S. pneumoniae, S. typhi, $H$. influenza, and $S$. sonnei. Leaf extracts showed a high inhibition zone compared to the stem extracts. Indeed, leaves methanol extract inhibited all selected bacteria except $S$. sonnei. Tables $2 \& 3$ show the antimicrobial activities of $K$. integra. The inhibition zones of $12.5 \mathrm{~mm}$ on $E$. coli and $18.5 \mathrm{~mm}$ on $S$. aureus were recorded with methanol leaf extracts at $100 \%$. Similar inhibition zones of 18,11 , and $12 \mathrm{~mm}$ were noted for S. typhi, H. influenza and S. pneumonia, respectively [16].

The extracts of $K$. integra inhibited also $S$. aureus $[11,13,18]$, E. coli $[10,11]$, Klebsiella pneumonia [13], S. typhi and $S$. pneumoniae [23]. In contrast, a largest inhibition zone of $52 \mathrm{~mm}$ was observed against $E$. coli, but $S$. aureus showed resistance [18]. The biggest inhibition zone seen could be attributed to high concentration used of leaves powder (300 $\mathrm{mg} / \mathrm{ml}$ ). The Table 4 shows antibacterial activity within three solvents of leaf extracts. Significance was seen within solvents, but not for bacteria. Antibacterial sensitivity results of stem and leaf extracts by agar well diffusion methods showed that leaf extracts were more effectives compared to the stem extract. Leaves and stem by using water solvent showed only antimicrobial activity against E. coli. (Tables $2-5)$. Contrastingly, methanol extracts of $K$. integra had no effect $E$. coli [13]. Sarkar, et al. [11] extracted phytochemicals from $K$. blossfeldiana that were active against $E$. coli, $S$. aureus, and $S$. pneumoniae at low concentration of $0.25 \mathrm{mg} / \mathrm{ml}$. In a study conducted by Biswas, et al. [9], root extracts were found to be the most effective antibacterial agents. Therefore, from the present results, methanol leaf extract can be used as antimicrobial agent against the tested bacteria. Table 6 shows comparison of methanol extract of leaves and stem effect on bacteria.

\begin{tabular}{|c|c|c|c|c|c|c|}
\hline & \multicolumn{3}{|c|}{ Methanol } & \multicolumn{3}{c|}{ Distilled water } \\
\hline Bacterium & $\mathrm{E} 1,100 \%$ & $\mathrm{E} 2,100 \%$ & Mean & $\mathrm{E} 1,100$ & $\mathrm{E} 2,100$ & Mean \\
\hline S. typhi & 21 & 20 & 20.5 & 0 & 0 & 0 \\
\hline S. aureus & 19 & 18 & 18.5 & 0 & 0 & 0 \\
\hline H. influenza & 16 & 17 & 17.5 & 0 & 0 & 0 \\
\hline S. pneumoniae & 13 & 12 & 12.5 & 0 & 0 & 0 \\
\hline E. coli & 12 & 13 & 12.5 & 14 & 15 & 14.5 \\
\hline S. sonnei & 0 & 0 & 0 & 0 & 0 & 0 \\
\hline
\end{tabular}

Table 2: Antimicrobial activity of Kalanchoe integra leaf extracts, E: experiment.

\begin{tabular}{|c|c|c|c|c|c|c|}
\hline & \multicolumn{3}{|c|}{ Methanol } & \multicolumn{2}{c|}{ Distilled water } \\
\hline Bacterium & $\mathrm{E} 1,100 \%$ & $\mathrm{E} 2,100 \%$ & Mean & $\mathrm{E} 1,100 \%$ & $\mathrm{E} 2,100 \%$ & Mean \\
\hline S. typhi & 18 & 17 & 17.5 & 0 & 0 & 0 \\
\hline S. aureus & 9 & 10 & 9.5 & 0 & 0 & 0 \\
\hline H. influenza & 13 & 14 & 13.5 & 0 & 0 & 0 \\
\hline S. pneumoniae & 10 & 11 & 10.5 & 0 & 0 & 11.5 \\
\hline E. coli & 9 & 10 & 9.5 & 11 & 12 & 0 \\
\hline S. sonnei & 0 & 0 & 0 & 0 & 0 & \\
\hline
\end{tabular}

Table 3: Antimicrobial activity of Kalanchoe integra stem extracts, E: experiment.

\begin{tabular}{|c|c|c|c|c|c|c|}
\hline Source of variation & SS & Df & MS & F & P-value & F crit \\
\hline Bacteria & 140.903 & 5 & 28.18 & 0.89 & 0.52 & 3.32 \\
\hline Solvents & 638.361 & 2 & 319.18 & 10.11 & 0.003 & 4.102 \\
\hline Error & 315.639 & 10 & 31.56 & & & \\
\hline Total & 1094.9 & 17 & & & & \\
\hline
\end{tabular}

Table 4: Effect within three solvents of leaf extracts. Variable ration (F test) for methanol, petroleum ether and distilled water SS: Sum of square, DF: degree of freedom, MS: mean square, F: crit: F critical. 


\section{Open Access Journal of Microbiology \& Biotechnology}

\begin{tabular}{|c|c|c|c|c|c|c|}
\hline Source of variation & SS & Df & MS & F & P-value & F crit \\
\hline Bacteria & 88.66 & 5 & 17.7 & 0.9 & 0.5 & 3.32 \\
\hline Solvents & 344.08 & 2 & 172.04 & 9.01 & 0.00477 & 4.1 \\
\hline Error & 190.75 & 10 & 19.01 & & & \\
\hline Total & 623.5 & 17 & & & & \\
\hline
\end{tabular}

Table 5: Effect within three solvents of stem extracts. Variable ration (F test) for methanol, petroleum ether and distilled water SS: Sum of square, DF: degree of freedom, MS: mean square, F: crit: F critical.

\begin{tabular}{|c|c|c|}
\hline & Variable 1 & Variable 2 \\
\hline Mean & 13.6 & 33.08 \\
\hline Variance & 56.26 & 6 \\
\hline Observations & 6 & \\
\hline Pooled variance & 45.05 & \\
\hline Hypothesized mean difference & 0 & \\
\hline Df & 10 & \\
\hline $\mathrm{t}$ Stat & 0.92 & \\
\hline $\mathrm{P}(\mathrm{T}<\mathrm{t}$ ) two-tail & 0.37 & \\
\hline $\mathrm{t}$ Critical two-tail & 2.22 & \\
\hline
\end{tabular}

Table 6: Comparison of methanol extract of leaves and stems effect on bacteria.

\section{Conclusion}

The screening of phytochemicals of $K$. integra revealed that leaf and stem consisted of phenols, flavonoids, and saponins. The methanol leaf crude extract of $K$. integra possesses an excellent antibacterial activity against E. coli, S. typhi, H. influenza, S. pneumoniae, and S. aureus. S. sonnei has shown a resistance on both leaf and stem extracts. As the present experimental studies showed a good antibacterial activity of both leaves and stem, the extracts have to be tested to other bacteria-causing diseases. In vivo and toxicity studies have also to be conducted in order to see the possibility of developing a drug from the plant.

\section{Acknowledgements}

The authors thank INES Ruhengeri for availing facilities and NCST for financial support.

\section{Funding}

National Commission of Science and Technology (Rwanda).

\section{References}

1. Oladeji 0 (2016) The characteristics and roles of medicinal plants: Some important medicinal plants in
Nigeria. Nat Prod Ind J 12(3): 102.

2. Julius AGI, Charles A, Samuel NE, Ansong AD, Mahmood $S$, et al. (2014) Nutraceutical with anti-inflammatory Activity for the management of airway remodeling in bronchial in Bronchial Asthma: Kalanchoe integra Var. crenata (Andr.) cuf leaf extract. Pharmacology and Pharmacy 5(3): 250-261.

3. Juda M, Korona-Glowniak I, Prystupa A, Malm A (2018) Streptococcus pneumoniae as an agent of urinary tract infection. J Pre Clin Clin Res 12(3): 87-88.

4. Guo Y, Song G, Sun M, Wang J, Wang Y, et al. (2020) Prevalence and therapies of antibiotic-resistance in Staphylococcus aureus. Front Cell Infect Microbiol 10: 107.

5. Reygaert WC (2018) An overview of the antimicrobial resistance mechanisms of bacteria. AIMS Microbiol 4(3): 482-501.

6. Akram J, Khan AS, Khan HA, Gilani SA, Akram SJ, et al. (2020) Extensively drug-resistant (XDR) typhoid: evolution, prevention, and its management. BioMed Research International 1(9): 34-58.

7. Olaimat AN, Al-Holy MA, Abu Ghoush MH, Abu Hilal HM, Al-Nabulsi AA, et al. (2019) Population dynamics 


\section{Open Access Journal of Microbiology \& Biotechnology}

of Salmonella spp. and Shigella spp. in ready-to-eat Mediterranean vegetable salads. Journal of Food Safety 40(1).

8. Abdellaoui S, Destandau E, Toribio A, Elfakir C, Lafosse M, et al. (2010) Bioactive molecules in Kalanchoe pinnata leaves: extraction, purification, and identification. Anal Bioanal Chem 398(3): 1329-1338.

9. Biswas SK, Chowdhury A, Das J, Hosen ZSM, Uddin R, et al. (2011) Literature review on pharmacological potentials of Kalanchoe pinnata (Crassulaceae). African Journal of Pharmacy and Pharmacology 5(10): 1258-1262.

10. Kamal Y, Ch BA, Uzair M, Irshad N, Yaseen M, et al. (2014) Different extracts of leaves of Kalanchoe Pinnata. Journal of Clinical Microbiology 6(4): 446-450.

11. Sarkar R, Mondal C, Bera R, Chakraborty S, Barik R, et al. (2015) Antimicrobial properties of Kalanchoe blossfeldiana: a focus on drug resistance with particular reference to quorum sensing-mediated bacterial biofilm formation. J Pharm Pharmacol 67(7): 951-962.

12. Bogucka-Kocka A, Zidorn C, Kasprzycka M, Szymczak G, Szewczyk K (2018) Phenolic acid content, antioxidant and cytotoxic activities of four Kalanchoe species. Saudi J Biol Sci 25(4): 622-630.

13. Richwagen N, Lyles JT, Dale BL F, Quave CL (2019) Antibacterial activity of Kalanchoe mortagei and K. Fedtschenkoi against ESKAPE pathogens. Front Pharmacol 10: 67.

14. Fernandes JM, Cunha LM, Azevedo EP, Lourenço EMG, Fernandes-Pedrosa MF, et al. (2019) Kalanchoe laciniata and Bryophyllum pinnatum: an updated review about ethnopharmacology, phytochemistry, pharmacology and toxicology. Revista Brasileira de Farmacognosia 29(4): 529-558.

15. Harborne JB (1984) Phytochemical Methods $2^{\text {nd }}$ (Edn.), Chapman and Hall Ltd, London, pp: 149-188.
16. Majaz QA, Tatiya AU, Khurshid M, Nazim S, Siraj S (2011) The miracle plant Kalanchoe pinnata: a phytochemical and pharmacological review. International Journal of Research in Ayurveda and Pharmacy 2(5): 1478-1482.

17. Singh RA, Jain A, Kaushal P, Bhatia D, Malik DK (2012) Antimicrobial and Antioxidant Activities of Kalanchoe pinnata Against Pathogens. Journal of Pharmacy Research 5(10): 5062-5063.

18. Manan M, Hussain L, Ijaz H, Qadir MI (2016) Report: Antimicrobial activity of Kalanchoe laciniata. Pak J Pharm Sci 29(4): 1321-1324.

19. Stefanowicz-Hajduk J, Hering A, Gucwa M, Hałasa R, Soluch A, et al. (2020) Biological activities of leaf extracts from selected Kalanchoe species and their relationship with bufadienolides content. Pharmaceutical Biology 58(1): 732-740.

20. Kolodziejczyk-Czepas J, Stochmal A (2017) Bufadienolides of Kalanchoe species: an overview of chemical structure, biological activity and prospects for pharmacological use. Phytochem Rev 16(6): 1155-1171.

21. Wadood A, Ghufran M, Jamal SB, Naeem M, Khan A, et al. (2013) Phytochemical analysis of medicinal plants occurring in local area of Mardan. Biochemistry \& Analytical Biochemistry 2(4): 2-5.

22. Yun YF, Hermanto F, Aisyah LS, Saputra TR, Hakim AR, et al. (2016) The phenolic compound from Kalanchoe blossfeldiana (Crassulaceae) leaf and its antiplasmodial activity against Plasmodium falciparum 3D7. Indonesian Journal of Chemistry 16(2): 156-161.

23. Dholaria M, Desai P (2014) Phytochemical Analysis and In-Vitro antibacterial activity of Kalanchoe Pinnata against human pathogens isolated from urinary tract infection. International Journal of Research and Scientific Innovation 1(7): 103-106. 